\title{
Does influenza immunisation cause exacerbations of chronic airflow obstruction or asthma?
}

\author{
J M Watson, J F Cordier, K G Nicholson
}

Influenza epidemics are regularly associated with excess mortality from respiratory, cardiovascular, and cerebrovascular disease and are associated with increased death rates from diabetes and neoplasia. ${ }^{12}$ Increasing age, the presence of certain chronic medical conditions, and residence in chronic care facilities are all associated with increasing morbidity and mortality from influenza. ${ }^{3-5}$ Many health authorities in Europe and North America recommend influenza immunisation of children and adults with chronic respiratory disease, including asthma, as well as a range of other conditions. ${ }^{6}$ Some also recommend immunisation of the elderly in communal residential accommodation such as nursing homes where rapid spread is likely to follow the introduction of infection. Some countries recommend influenza immunisation for all those aged over 65 years irrespective of their current health status.

Despite the guidance, uptake of influenza immunisation by those for whom it is recommended is low in many countries. ${ }^{78}$ This may be due to doubts on the part of some doctors and patients about the protective efficacy of the vaccine. These doubts may sometimes be understandable. To be effective the vaccine must match the currently circulating strains of influenza virus, but as the vaccine components have to be selected six or more months in advance of the influenza season, the match may not always be ideal. In addition, although influenza immunisation generally provides protection in healthy children and adults in the range of $60-90 \%$, and considerable evidence is mounting that it provides useful protection in most seasons for the elderly, ${ }^{9}$ only a limited amount of evidence is available that it provides a similar degree of protection in the groups with chronic disease for whom it is recommended.

Many patients are also disillusioned when the vaccine does not protect against other causes of influenza-like illness. A variety of respiratory pathogens may cause influenza-like illnesses and circulate frequently in the winter months. Respiratory syncytial virus (RSV) causes an annual winter epidemic, predominantly in infants, but is also responsible for considerable morbidity in older age groups, especially the elderly. ${ }^{10}$ Little difference has been reported in the symptoms observed in elderly people as a result of influenza or RSV infection. ${ }^{11}$ As patients who have received influenza vaccination are no less likely than those unvaccinated to succumb to other respiratory tract infections, a proportion will inevitably contract an infection in the week or two after immunisation and may attribute it to the vaccine. In addition, average annual influenza attack rates in the community during epidemics are estimated at $10-20 \%$, so most patients in any one year will be unaffected.

Concern about possible side effects of influenza immunisation have further reduced uptake rates. Precipitation of asthma or exacerbation of chronic airflow obstruction are prominent among the concerns of some patients and doctors and, as a result, in Britain neither the British Thoracic Society nor the National Asthma Campaign have endorsed the guidelines produced by the British Government recommending influenza vaccination in these patient groups. ${ }^{12}$ This brief review considers the evidence that currently used inactivated influenza vaccines may cause a worsening of respiratory symptoms; reports relating to both asthma and chronic airflow obstruction (chronic bronchitis, emphysema, chronic obstructive pulmonary/lung disease) have been considered.

\section{Role of viral respiratory infections}

An association between respiratory virus infections and exacerbations of asthma is well established, both in children ${ }^{1314}$ and adults. ${ }^{1516}$ Influenza virus has been specifically associated with precipitation of asthma ${ }^{141517}$ and may, along with other respiratory viruses, contribute to the pathogenesis of asthma. ${ }^{18}$ The mechanisms, however, leading to pathogenesis or precipitation of virally induced asthma are poorly understood. Respiratory virus infections have also been associated with exacerbations of chronic airflow obstruction in adults. ${ }^{19}$

Epidemic influenza virus activity in the community is associated with increased admissions to hospital and with increased mortality from all causes. Acute respiratory diseases are the major cause of the increase in hospital ad- 
missions during these periods and chronic pulmonary disorders (especially asthma, chronic obstructive pulmonary disease and emphysema) are the most common underlying conditions. ${ }^{20}$ Increases in deaths from both cardiovascular and respiratory disease contribute the largest part to the mortality during influenza epidemics, ${ }^{21}$ and deaths attributed to pneumonia and influenza are the commonest respiratory causes. ${ }^{4}$

\section{Live influenza vaccines}

There is relatively little information available on live attenuated influenza vaccines, although there has been a report of increased bronchial hyperresponsiveness in a study involving 14 normal subjects ${ }^{22}$ and uncontrolled studies of respiratory symptoms and pulmonary function in patients with asthma and chronic airflow obstruction ${ }^{23-26}$ who have received various live influenza vaccines have produced conflicting results. However, placebo controlled studies conducted by the British Medical Research Council, using spirometric tests and flow volume loops, revealed no adverse effects on pulmonary function. ${ }^{27}$

\section{Inactivated influenza vaccines}

ANECDOTAL REPORTS

In 1992 Hassan et al reported the exacerbation of asthma after influenza immunisation including three patients who had to be admitted to hospital. ${ }^{28}$ They concluded that influenza vaccine should not be offered to patients with stable asthma. In subsequent correspondence Daggett ${ }^{29}$ supported Hassan by reporting that he had admitted six asthmatic patients that winter who had become ill within 24 hours of immunisation. Subsequent correspondents disagreed citing contrary evidence. ${ }^{3031}$ More importantly, these anecdotal reports were based on small numbers and may represent findings that occurred by chance alone.

\section{SURVEILLANCE OF ADVERSE EVENTS}

Following the rapid distribution of influenza vaccine against $\mathrm{A} / \mathrm{New}$ Jersey/76 to 46 million Americans in response to the outbreak of swine influenza at Fort Dix in 1976, surveillance for side effects from the vaccine was carried out which revealed an apparent association with the Guillain-Barré syndrome. The data from the United States and Canada did not reveal evidence to suggest an increased occurrence of respiratory symptoms following vaccination. ${ }^{3233}$ This vaccine was monovalent, however, and probably not typical of most inactivated influenza vaccines. In the United Kingdom the Committee on Safety of Medicines received 990 reports of possible adverse reactions to influenza vaccines between 1963 and 1991; of these, only 26 were of cases of asthma or bronchospasm. Palache and van der Velden, from one of the vaccine manufacturers, reported the exceptionally low number of reports of asthma exacerbations received by the manufacturer following the administration of 40 million doses. ${ }^{31}$

Surveillance schemes for side effects associated with medicinal products, however, are dependent upon recognition and reporting by clinicians of conditions which might be associated with the administration of the product and considerable under-reporting occurs. Recognition of an associated side effect is made yet more difficult if the condition is very rare or very common.

OBSERVATIONAL STUDIES

Observational studies in patients with asthma and chronic airflow obstruction have been carried out in a wide range of settings. The results of these studies, which have looked at both pulmonary function (including bronchial reactivity following methacholine challenge) and the occurrence of respiratory or other symptoms, have been conflicting. Some, such as Ouellette and Reed ${ }^{34}$ in the mid 1960s and Anand et $a l^{35}$ in 1968 reported increases in bronchial reactivity in asthmatic subjects following immunisation. Bell et $a l^{36}$ reported a trend to a decrease in peak expiratory flow rate following immunisation of asthmatic children with an inactivated influenza vaccine in the late 1970 s but, in a subsequent study, ${ }^{37}$ they reported no such change in a similar group given a different inactivated influenza vaccine. Kava et al reported two studies in asthmatic subjects given inactivated influenza vaccine and observed no alterations in respiratory function..$^{3839}$

In a study of patients with chronic airflow obstruction Knowles $e t a l^{40}$ reported an increase in respiratory symptoms following inactivated vaccine but the study involved only 30 patients. Other uncontrolled trials on patients with chronic airflow obstruction and asthma have reported no appreciable increase in the occurrence of respiratory symptoms even if some aspects of respiratory function were observed to change.

Although these observational studies have been carried out in groups of patients with asthma or chronic airflow obstruction, the absence of controls or use of placebo, and the generally small numbers involved, make interpretation of the results and determination of their applicability to these groups of patients in general very difficult. Larger observational studies have been carried out in unselected groups of individuals such as the elderly ${ }^{41}$ and hospital staff ${ }^{4243}$; a small number of local or mild systemic side effects were reported in these studies but no respiratory symptoms were reported. Even in these larger studies, however, the numbers at risk of exacerbation of asthma or chronic airflow obstruction are likely to have been small and the significance of the mild systemic symptoms cannot be determined in the absence of a placebo group.

Egg allergy is a contraindication to influenza immunisation because of the traces of egg antigen contained in inactivated vaccines following their production in hens' eggs. Little information is therefore available about the 
effect of vaccination in asthmatics with egg allergy, but one small uncontrolled trial was reported by Murphy and Strunk ${ }^{44}$ who administered an inactivated influenza vaccine to six asthmatic children with egg allergy using a low dose incremental scheme: no subsequent respiratory symptoms were observed.

PLACEBO CONTROLLED TRIALS

Placebo controlled trials remain the only reliable way to answer the questions about the side effects of influenza vaccination and to distinguish the results observed from those that might have occurred by chance alone or those that were the result of coincident other infections or resulted from the placebo effect of the procedure rather than the vaccine product itself. In view of the infrequency with which any significant side effects to influenza immunisation occur (local soreness apart), large numbers are necessary which makes the costs of a study high. To address these questions in those with asthma or chronic airflow obstruction presents further difficulties in recruitment and may also raise, in the view of some, insurmountable ethical issues. Consequently, few such studies have been carried out. These studies have not attempted to determine the protective efficacy of the vaccine against influenza related illness in the influenza season following immunisation as rather different methodologies are required to do this.

In a randomised double blind placebo controlled crossover trial in 336 elderly people in the 1988/89 influenza season Margolis et $a l^{45}$ reported no significant difference between inactivated trivalent split antigen influenza vaccine and saline placebo with respect to the proportion of subjects reporting disability or systemic symptoms. Although $13.2 \%$ of subjects reported coryzal symptoms in the week following immunisation and $6.6 \%$ cough, the corresponding figures in those who received placebo were $10.2 \%$ and $5.1 \%$, respectively $(p=0.27$ and 0.62$)$. Non-specific symptoms of feverishness, fatigue, malaise, myalgia, headache, and nausea were reported by between $4.5 \%$ and $8.0 \%$ of vaccinated subjects which was not significantly more frequent than in those who had received placebo. However, $20.1 \%$ of vaccinated subjects reported a sore arm compared with $4.9 \%$ of those who received placebo $(\mathrm{p}<0.001)$. No information is provided about the number of subjects with asthma or chronic airflow obstruction although two thirds of the subjects, who were randomly sampled from ambulatory outpatients of a Veterans hospital, were reported to have "chronic illness that would predispose them to increased influenza morbidity". The authors acknowledged that their results, derived in an exclusively elderly population, may not be generally applicable to young adults or children.

Stenius-Aarniala et al conducted a study in 1981 of 318 adults with chronic asthma in Finland. Subjects were randomised to receive inactivated split bivalent influenza vaccine or saline placebo. ${ }^{46}$ The subjects, who ranged in age between 20 and 73 years (mean 47-48 years), had an average nine year history of asthma. In the week following immunisation no significant difference in the mean peak expiratory flow rate in the morning, noon or evening was observed between the two groups. Reports of dyspnoea, cough, and production of sputum were "similar" (data not published) between the two groups as was the need for medication. No influence on side effects to vaccination was found when the data were analysed separately by age, sex, duration of disease, atopic status, history of attacks of asthma induced by viral infections, diurnal variation of baseline peak expiratory flow of $20 \%$ or more, or patients receiving continuous steroid medication. Children and patients with egg allergy or known hypersensitivity to influenza vaccines were excluded but it is not indicated how many subjects were considered to fall into this latter category. Patients in this study had careful optimisation of their treatment before the study and the authors suggest that this could have improved bronchial stability and diminished the sensitivity of patients to any adverse effects of vaccination.

Kava $e t a l^{47}$ in the early 1980 s investigated the effect of vaccine or saline placebo on respiratory functions in 27 patients with mild to moderate asthma. Although increased bronchial reactivity was observed in four of the 16 asthmatics given vaccine, it was also seen in five of the 11 asthmatic subjects who received saline. The authors concluded that natural infection or allergen exposure could not be ruled out as the cause of these results. Campbell and Edwards ${ }^{48}$ gave both inactivated trivalent influenza vaccine and saline placebo to 28 asthmatic subjects in a crossover study conducted over three weeks. Both respiratory symptoms and peak expiratory flow rate were recorded. A mean reduction in evening peak expiratory flow of $168 \mathrm{l} / \mathrm{min}$ was observed during the week after vaccination which just reached statistical significance, but no change in symptoms occurred. Neither of these studies was large enough to provide results that could be reliably extended to the asthmatic population in general.

Govaert et $a l^{49}$ randomised 1806 elderly people in 1991 to receive inactivated influenza vaccine or placebo in a double blind study. Patients living in residential accommodation were excluded. The vaccine and placebo groups were similar with respect to age, sex, previous vaccination, and risk status (including heart and lung conditions and diabetes mellitus). Adverse reactions were reported on a postal questionnaire completed four weeks after vaccination. About $11 \%$ of both the vaccine and placebo group had underlying chronic pulmonary disease, including 179 with asthma, chronic airflow obstruction and/or bronchiectasis (ThME Govaert, personal communication). Overall, $23.2 \%$ of patients who received the vaccine reported side effects compared with $14.1 \%$ who received placebo $(\mathrm{p}=$ 0.82 ). Local reactions at the site of the vaccination such as swelling, itching and pain were significantly more common in the vaccinated group $(17.5 \%$ versus $7.3 \%, \mathrm{p}<0.001)$. Systemic 
reactions such as fever, headache, or malaise were no more common, however, in the vaccinated group than in the controls $(11 \%$ versus $9.4 \%, \mathrm{p}=0.34)$. The occurrence of respiratory symptoms was not specifically sought in this study although one subject who had received placebo reported mild dyspnoea (ThME Govaert, personal communication). Women reported more side effects than men although fever, the only adverse reaction studied that could be measured objectively, was reported by similar numbers of men and women. This study provided no information about the likelihood of side effects in younger adults and children, but did find a suggestion that side effects became less likely with increasing age. The authors felt that this finding may have been biased by the fact that there were many fewer patients in the older age groups. Previous vaccination status made no difference to the likelihood of adverse reactions.

\section{Conclusions}

Influenza vaccine is usually given at the time of year when the number of respiratory virus infections in the community is beginning to increase and a certain proportion of patients would be expected to experience such infections after immunisation by chance alone. It is not surprising, therefore, that anecdotal experience dominates individual clinician and patient attitudes to the vaccine. In addition, in some years the protection offered by the vaccine may be limited as a result of a poor match between the vaccine and circulating influenza viruses. This limitation to the effectiveness of the vaccine, and the fact that influenza epidemics generally affect only a minority of patients in any one year, may influence the relative importance that clinicians attach to the potential side effects of influenza immunisation.

The currently available evidence indicates that respiratory viral infections may precipitate asthma or cause exacerbation of chronic airflow obstruction. Some live influenza virus vaccines have been associated with lower respiratory tract symptoms and pulmonary function abnormalities but placebo controlled trials have revealed no adverse effects on pulmonary function. With inactivated influenza vaccines conflicting results have been obtained in uncontrolled studies when pulmonary function has been monitored before and after immunisation. The very low number of reports received by both vaccine manufacturers and governmental agencies of respiratory symptoms following influenza immunisation suggests that these vaccines have, at most, a very limited role in causing respiratory side effects.

The small number of placebo controlled trials do not support a significant role for inactivated influenza vaccines in exacerbating asthma or chronic airflow obstruction. Although some limited evidence of changes in pulmonary function was observed in some of the earlier studies following immunisation, this was not generally observed in later studies. A greater proportion of local reactions has been reported in vaccine recipients than in subjects receiving saline placebo, but no significant increase in systemic or respiratory symptoms has been reported following influenza vaccination. However, the number of asthmatic subjects in even the largest of the studies was small. If a side effect was observed in $5 \%$ of subjects receiving placebo, 474 subjects in both the vaccine and placebo groups would be needed to detect, with $80 \%$ power, a statistically significant effect in $10 \%$ or more of the vaccinated group. Even with study numbers this large a side effect which occurred in nearly twice the proportion of vaccinated subjects than controls might not be detected.

The currently available information provides no evidence that exacerbation of these conditions following administration of inactivated influenza vaccines occurs more often than by chance alone. However, further studies are needed. The number of placebo controlled trials on inactivated influenza vaccine is small, the number of subjects in some of the trials is very small, and the amount of data relating to the occurrence of respiratory symptoms in patients with asthma or chronic airflow obstruction is limited. Future studies should be randomised, double blind, and placebo controlled, they should recruit subjects of all ages with asthma or chronic airflow obstruction, and should be large enough to demonstrate real effects if they exist. Follow up should include both objective measures of pulmonary function such as spirometric tests as well as the occurrence of respiratory symptoms. The positive results of recent major case control studies on the protective effect of influenza immunisation in the elderly ${ }^{9}$ are likely to influence the decision of some clinicians to vaccinate their patients. Only conclusive evidence from one or more well conducted studies of the side effects of the vaccine will persuade some sceptical clinicians caring for anxious patients with respiratory disease that the risk of side effects from the vaccine is outweighed by the risk of influenza itself. The weight of the current evidence, however, supports the majority of clinicians who continue to follow the recommendations of authors in both Britain and the United States ${ }^{5051}$ and offer influenza immunisation to their patients at increased risk of the complications of influenza infection.

This work was undertaken within the framework of the European Scientific Working Group on Influenza.

1 Housworth J, Langmuir AD. Excess mortality from epidemic influenza, 1957-1966. Am f Epidemiol 1974;100:40.

2 Ashley J, Smith T, Dunnell K. Deaths in Great Britain associated with the influenza epidemic of 1989/90. Population Trends 1991;65:16-20.

3 Glezen WP. Serious morbidity and mortality associated with influenza epidemics. Epidemiol Rev 1982;4:25-44.

4 Barker WH, Mullooly JP. Pneumonia and influenza deaths during epidemics. Arch Intern Med 1982;142:85-9.

5 Nguyen-van-Tam JS, Nicholson KG. Influenza deaths in Leicestershire during the 1989-90 epidemic: implications Leicestershire during the 1989-90 epidemic: implicat
for prevention. Epidemiol Infect 1992;108:537-45.

6 Nicholson KG, Snacken R, Palache AM. Influenza immunisation policies in Europe and the United States.
mons Vaccine 1995;13:365-9.

7 Centers for Disease Control. Influenza vaccination levels 1989-1991 (editorial). ҒAMA 1992;268:2360.

8 Nguyen-van-Tam JS, Nicholson KG. Influenza immunisation; vaccine offer, request and uptake in high-risk patients during the 1991/2 season. Epidemiol Infect 1993; 111:347-55. 
9 Monto AS. Influenza vaccines for the elderly (editorial). $N$ Engl $\mathcal{F}$ Med 1994;331:807-8.

10 Fleming DM, Cross KW. Respiratory syncytial virus or infuenza? Lancet 1993;342:1507-10

11 Nicholson KG, Baker DJ, Farquhar A, Hurd D, Kent J, Smith SH. Acute upper respiratory tract viral illness and influenza immunization in homes for the elderly. Epidemiol Infect 1990;105:609-18.

12 Department of Health Welsh Office, Scottish Office Home and Health Department, DHSS (Northern Ireland). Immunisa

13 McIntosh K, Ellis EF, Hoffman LS, Lybass TG, Eller JJ, Fulginiti VA. The association of viral and bacterial Jespiratory infections with exacerbations of wheezing in respiratory infections with exacerbations of wheezing
young asthmatic children. Pediatrics 1973;82:578-90.

14 Minor TE, Dick EC, De Meo AN, Oullette JJ, Cohen M, Reed CE. Viruses as precipitants of asthmatic attacks in children. $\mathcal{F} A M A$ 1974;227:292-8.

15 Beasley R, Coleman ED, Hermon Y, Holst PE, O’Donnell TV, Tobias $M$. Viral respiratory tract infection and exacerbations of asthma in adult patients. Thorax $1988 ; \mathbf{4 3}$ : 679-83.

16 Nicholson KG, Kent J, Ireland DC. Respiratory viruses and exacerbations of asthma in adults. BMF 1993;307:982-6.

17 Kondo S, Abe K. The effects of influenza virus infection $\mathrm{FEV}_{1}$ in asthmatic children: the time-course study. Chest 1991;100:1235-8.

18 Busse WW. The contribution of viral respiratory infections to the pathogenesis of airway hyperreactivity. Chest 1993; 93:1076-82.

19 Smith CB, Golden CA, Kanner RE, Renzetti AD. Association of viral and Mycoplasma pneumoniae infections with acute respiratory illness in patients with chronic obstructive pulmonary diseases. Am Rev Respir Dis 1980; 121:225-32.

20 Glezen P, Decker M, Perrotta M. Survey of underlying conditions of persons hospitalized with acute respiratory disease during influenza epidemics in Houston, 19781981. Am Rev Respir Dis 1987;136:550-5.

21 Curwen M, Dunnell K, Ashley J. Hidden influenza deaths: 1989-90. Population Trends 1990;Autumn:31-3.

22 Laitinen LA, Elkin RB, Empey DW, Jacobs L, Mills J, Nadel JA. Bronchial hyperresponsiveness in normal subjects during attenuated influenza virus infection. Am Rev Respir Dis 1991;143:358-61.

23 Atmar RL, Bloom K, Keitel W, Couch RB, Greenberg SB. Effect of live attenuated, cold recombinant (CR) influenza Effect of live attenuated, cold recombinant (CR) influenza
virus vaccines on pulmonary function in healthy and virus vaccines on pulmonary function

24 Prevost JM, Vereerstraeten-Schnerber J, Lamy F, De Koster JP. Live attenuated influenza virus vaccines in patients with chronic broncho-pulmonary diseases. Scand $\mathcal{F}$ Respir Dis 1975;56:58-69.

25 Zeck R, Solliday N, Kehoe N, Berlin B. Respiratory effects of live influenza virus vaccine. Am Rev Respir Dis 1976; 114:1061-7.

26 Winson IG, Smit JM, Potter CW, Howard P. Studies with live attenuated influenza virus in chronic bronchitis. Thorax 1977;32:726-8.

27 MRC advisory group on pulmonary function tests in relation to live influenza vaccines. Trials of live attenuated influenza virus vaccine in patients with chronic obstructive airways disease. $B r \mathcal{F}$ Chest Dis 1984;78:236-47.

28 Hassan WU, Henderson AF, Keaney NP. Influenza vaccination in asthma (letter). Lancet 1992;339:194.

29 Daggett P. Influenza and asthma (letter). Lancet 1992;339: 367.

30 Ong ELC, Bilton D, Abbott J, Webb AK, McCartney $\mathrm{RA}$, Caul EO. Influenza vaccination in adults with cystic fibrosis. BMF 1991;303:557.
31 Palache AM, van der Velden JW. Influenza vaccination in asthma (letter). Lancet 1992;339:741.

32 Retailliau HF, Curtis AC, Storr G, Caesar G, Eddins DI Hattwick M. Illness after influenza vaccination reported through a nationwide surveillance system, 1976-1977. Am f Epidemiol 1980;111:270-8.

33 Rohrer JW, Hamilton G. Surveillance of the swine influenza vaccination program at the Royal Military College, Kingston. Can Med Assoc f 1978;118:1528-30.

34 Ouellette JJ, Reed CE. Increased response of asthmatic subjects to methacholine after influenza vaccine. 7 Allergy 1965;36:558-63.

35 Anand SC, Itkin IH, Kind LS. Effect of influenza vaccine on methachlone (Mecholyl) sensitivity in patients with asthma of known and unknown origin. F Allergy 1968;42: 187-92.

36 Bell TD, Chai H, Berlow B, Daniels G. Immunization with killed influenza virus in children with chronic asthma. Chest 1978;73:140-5.

37 Bell TD, Leffert F, McIntosh K. Monovalent influenza $\mathrm{A} / \mathrm{New}$ Jersey/76 virus vaccines in asthmatic children: pulmonary function and skin tests for allergy. F Infect $D$ is 1977:136:S612-5.

38 Kava T, Laitinen LA. Effects of killed and live attenuated influenza vaccine on symptoms and specific airway conductance in asthmatics and healthly subjects. Allergy 1985 40:42-7.

39 Kava T. Acute respiratory infection, influenza vaccination and airway reactivity in asthma. Eur $\mathcal{F}$ Respir Dis Supp 1987;150:1-38

40 Knowles GK, Taylor P, Turner Warwick M. A comparison of antibody responses to Admune inactivated influenza vaccine in serum and respiratory secretions of healthy non-smokers, healthy cigare chronic bronchitis. Br f Dis Chest 1981;75:283-90.

41 Margolis KL, Poland GA, Nichol KL, MacPherson DS, Meyer JD, Korn JE, et al. Frequency of adverse reactions after influenza vaccination. Am f Med 1990;88:27-30.

42 Scheifele DW, Bjornson G, Johnston J. Evaluation of adverse events after influenza vaccination in hospital personnel. Can Med Assoc $\mathcal{F}$ 1990;142:127-30.

43 Al-Mazrou A, Scheifele DW, Soong T, Bjornson G. Comparison of adverse reactions to whole-virion and splitvirion influenza vaccines in hospital personnel. Can Med virion influenza vaccines $1991 ; \mathbf{1 4 5}: 213-8$.

44 Murphy KR, Strunk RC. Clinical and laboratory observations: safe administration of influenza vaccine in asthmatic children hypersensitive to egg proteins. F Pediat 1985;106:931-3.

45 Margolis KL, Nichol KL, Poland GA, Pluhar RE. Frequency of adverse reactions to influenza vaccine in the elderly: randomized, placebo-controlled trial. $\mathcal{F} A M A$ 1990;264: $1139-41$

46 Stenius-Arniala B, Huttunen JK, Pyhala R, Haahtela T, Jokely P, Jukkara A, et al. Lack of clinical exacerbations in adults with chronic asthma after immunization with killed influenza virus. Chest 1986;89:786-9.

47 Kava T, Lindqvist A, Karjalainen J, Laitinen L. Unchanged bronchial reactivity after killed influenza virus vaccine in adult asthmatics. Respiration 1987;51:98-104.

48 Campbell BG, Edwards RL. Safety of influenza vaccination in adults with asthma. Med $\mathcal{F}$ Aust 1984;140:773-5.

49 Govaert ThME, Dinant GJ, Aretz K, Masurel N, Sprenger MJW, Knottnerus JA. Adverse reactions to influenza vaccine in elderly people: randomised double blind pacebo controlled trial. BMF 1993;307:988-90.

50 Wilson R. Influenza vaccination (editorial). Thorax 1994, 49:1079-80.

51 Rothbarth PH, Kempen BM, Sprenger MJW. Sense and nonsense of influenza vaccination in asthma and chronic obstructive pulmonary disease. Am F Respir Crit Care Med 1995;151:1682-6. 